\title{
Design, Development and Thermal Performance Analysis of Ultra-Low Heat Loss Triple Vacuum Glazing
}

\author{
Saim Memon ${ }^{1}$, Philip C. Eames ${ }^{2}$ \\ ${ }^{1}$ London South Bank University, London (UK) \\ 2 Loughborough University, Loughborough (UK)
}

\begin{abstract}
Heat loss through windows of buildings is one of the significant causes of high-energy consumption that require intervention to advance their thermal performance in a move towards net-zero energy buildings. Highperformance triple vacuum glazing features ultra-low heat loss that maintains the transparency, regardless of tiny pillar spots, and slimness due to its narrow evacuated cavities. This study reports the design and development of high-vacuum system with the modified vacuum cup which provides an effective pump-out hole sealing and has an achievable vacuum pressure of $4.02 \times 10^{-5} \mathrm{~Pa}$. A new dual-edge seal (low temperature melt $186^{\circ} \mathrm{C}$ ) consists of Cerasolzer CS186 alloy as a main and J-B Weld epoxy steel adhesive as a support seal is developed and the triple vacuum glazing (area of $300 \times 300 \mathrm{~mm}$ ) samples are fabricated, in which the vacuum pressure of $4.8 \times 10^{-2} \mathrm{~Pa}$ is achieved. A 3D FEM of the fabricated triple vacuum glazed is developed and the centre-of-pane and overall $\mathrm{U}$-value of $0.33 \mathrm{Wm}^{-2} \mathrm{~K}^{-1}$ and $1.05 \mathrm{Wm}^{-2} \mathrm{~K}^{-1}$, respectively, are predicted.
\end{abstract}

Keywords: Smart Window, Vacuum Glazing, High-Vacuum System, Finite Element Modelling, Sustainable Building, Solar Energy, Energy Efficiency.

\section{Introduction}

An increase of global annual average surface temperature to $0.99^{\circ} \mathrm{C}$ in 2016 (Lee et al, 2017) is due to the $\mathrm{CO}_{2}$ level that reached $400 \mathrm{ppm}$, breaking the 1950's level threshold of $300 \mathrm{ppm}$ (Andric et al, 2017). More than $30 \%$ of the total global final energy consumption is in the building sector (Piccolo and Simone, 2015). Advanced insulation technologies and retrofitting measures have already minimized the building energy consumption but yet require more energy-efficient technologies that bring the building sector towards zerocarbon sustainable buildings (Memon and Eames, 2017). To achieve this, glazed windows are of particular interest in this paper specifically in cold arid climate. It's one thing a need of high visual light transmittance, above $70 \%$, and reasonable solar heat gain coefficient, G-Value, range from 0.4 to 0.7 through glazed windows and another thing a significant heat loss through glazed windows. The heat loss through glazed windows is the result of the heat transfer by conduction, convection and radiation and is determined by the thermal transmittance value (U-value). Smart glazing technologies such as thermotropic glazing or double air-filled glazing have identical U-values of $2.7 \mathrm{Wm}^{-2} \mathrm{~K}^{-1}$ (Allen et al, 2017). A smart double glazing with low-e glass and a photochromic coated glass achieved a G-value of 0.26 and U-value of $1.58 \mathrm{Wm}^{-2} \mathrm{~K}^{-1}$ (Wu et al, 2017). Glazed windows with cavities filled with heavy gases (Argon, Krypton or Xenon) improves thermal performance from 3.5 to $1.4 \mathrm{Wm}^{-2} \mathrm{~K}^{-1}$, depends on the cavity thickness, e.g. the best predicted U-value of the Xenon-gas filled double glazing at the cavity width of $20 \mathrm{~mm}$ was reported to be $1.4 \mathrm{Wm}^{-2} \mathrm{~K}^{-1}$ (Manz, 2008). Aerogel-gas filled double glazing made of granular aerogel sandwiched in a $16 \mathrm{~mm}$ wide polymethyl methacrylate (PMMA) double skin-sheet and two 12mm layers of krypton gas between two glass sheets (total cavity thickness of $38 \mathrm{~mm}$ ) achieved the best possible U-value of $0.5 \mathrm{Wm}^{-2} \mathrm{~K}^{-1}$ (Baetens et al, 2011). Due to its semi transparency, greater thickness than conventional glazing and high cost of aerogel materials, they were not deployed in the UK. 


\section{Saim Memon}

Vacuum glazing has the potential to provide a clear transparent view except for tiny dots due to support pillars, narrow width of about $8.3 \mathrm{~mm}$ and the space between the two glass sheets is evacuated to a pressure of less than $0.1 \mathrm{~Pa}$ rather than including any medium or material (Memon, 2014). With vacuum glazing, the centre-of-pane U-value can be reduced down to $0.8 \mathrm{Wm}^{-2} \mathrm{~K}^{-1}$ (Eames, 2008) when evacuating the space between two low-e coated glass panes, e.g. tin-oxide coating emissivity of 0.15 . A pressure of less than 0.1 Pa reduces gaseous conductive and convective heat transfer to a negligible level (except heat conduction through support pillars and edges) and radiative heat transfer can be reduced using soft low-e coatings, e.g. silver coating emissivity of 0.02 . To reduce the U-value below $0.5 \mathrm{Wm}^{-2} \mathrm{~K}^{-1}$, a concept of triple vacuum glazing was reported by Wuethrich (2005). In this paper, the design, development, fabrication methods and U-value predictions of a new dual-edge sealed triple vacuum glazing are reported. A dual-edge seal is hermetic and it consists of Cerasolzer alloy CS186 as a main seal and J-B weld epoxy steel resin as a support seal (Memon et al, 2015). A triple vacuum glazing consists of three $\mathrm{SnO}_{2}$ coated k-glass sheets, air-tight sealed around the edges, with evacuated two narrow $(0.15 \mathrm{~mm}$ high) cavities having a pressure of $0.01 \mathrm{~Pa}$. A regular square array of stainless steel support pillars, typically $0.15 \mathrm{~mm}$ high and $0.3 \mathrm{~mm}$ diameter spaced at $24 \mathrm{~mm}$, maintains the separation of three glass sheets under the effects of atmospheric and vacuum pressure.

\section{High-Vacuum System Design and Development}

A high-vacuum system was designed for the fabrication of ultra-low heat loss triple vacuum glazing as shown in Fig. 1. A dry type turbo-molecular with backing pump with an achievable pressure of $5 \times 10^{-6} \mathrm{~Pa}$ was chosen. This is because the vacuum pump should be of an oil free/dry type as the contamination in the oil type with oil molecules could occur on the surfaces of tubes, valves, hose and/or vacuum cup preventing an effective vacuum level from being achieved. A turbo-molecular vacuum pump has a pumping speed of 200-300litre/min. The ATV (Atmosphere to Vacuum) transducer type 979, connected to the PDR 900 digital pressure measurement readout, is used in the present study for the measurement of vacuum pressure in the designed vacuum system. This pressure gauge is located at the closest possible location to the vacuum cup to measure the approximate pressure in the cavity/cavities of the triple vacuum glazing as illustrated in Fig. 2. The ATV transducer enables measurement of a wide pressure range from ultrahigh vacuum $\left(1.33 \times 10^{-8} \mathrm{~Pa}\right)$ to atmospheric pressure $\left(101.33 \times 10^{3} \mathrm{~Pa}\right)$. In order to regulate or isolate the gas load either from the vacuum pump or Nitrogen gas cylinder, a Swagelok adapter is assembled; angle valves were located at the two positions of $\mathrm{U}$ joint as shown in Fig. 1.

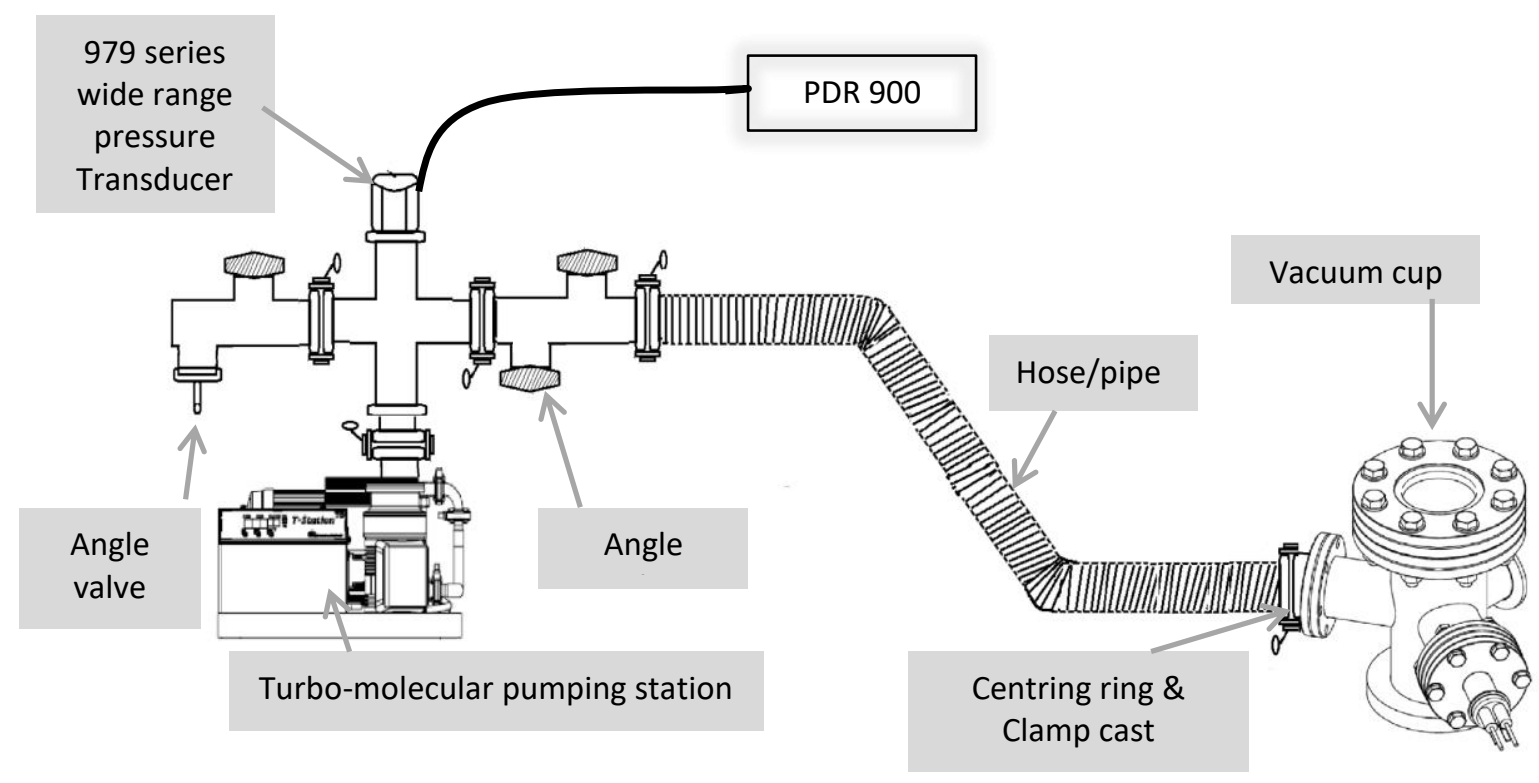

Fig. 1: A schematic diagram of the vacuum system showing the turbo-molecular pump connected via hose to the vacuum cup. 


\section{Saim Memon}

The laboratory vacuum glazing fabrication system developed as shown in Fig. 2. This is based on the design presented in Fig. 1. The vacuum system was experimentally tested and the minimum achievable vacuum pressure was recorded to be $4.35 \times 10^{-5} \mathrm{~Pa}$. This deviates by $7.7 \%$ with the ultimate vacuum pressure of the turbo molecular pump due to the internal space conductance.

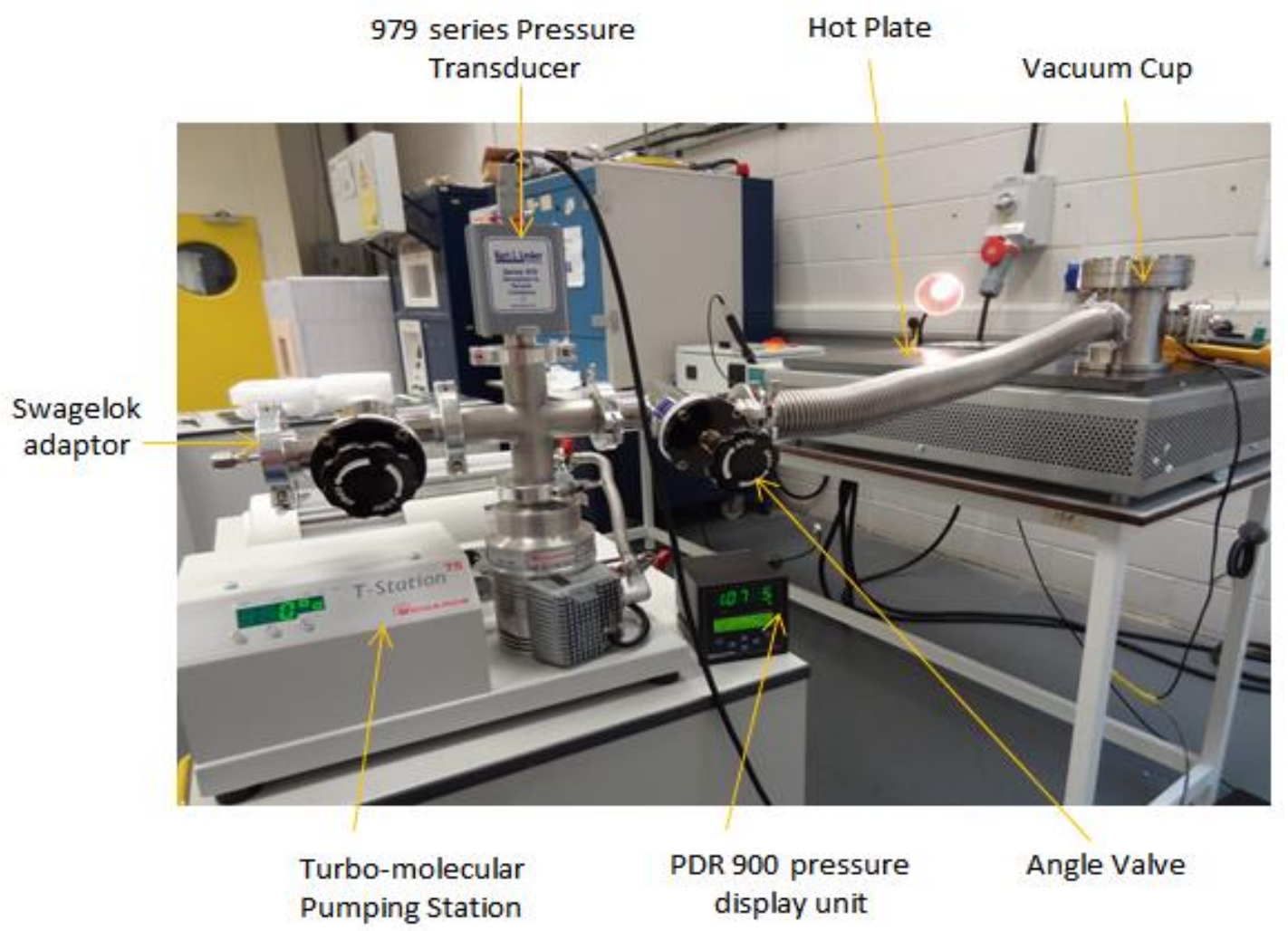

Fig. 2: A photograph of the vacuum system developed based on the design presented in Fig.1.

The vacuum cup was designed and constructed with dimensions of $100 \mathrm{~mm}$ diameter and $150 \mathrm{~mm}$ height for evacuation and pump-out hole sealing of the triple vacuum glazing as shown in Fig. 3. CF (conflat) metal seal flanges were used to provide an ultra-high vacuum (more than $1 \times 10^{-7} \mathrm{~Pa}$ ) seal between the two components. Only two CF flanges were used on the vacuum cup with an $\mathrm{O}$ ring seal on other joints. The modified pump-out mechanism, as illustrated in Fig. 3, requires a square cover slip (around 10x10mm) pre-soldered with Cerasolzer alloy (CS186) to be placed over the pump-out hole. Heating block, cartridge heater and thermocouple mounted on a metallic rod controlled through a supporting Y shaped block provides up and down motion of up to $10 \mathrm{~mm}$. A K type thermocouple fixed to the heating block measures the approximate glass disc/square temperature. Heat transfer at high vacuum occurs through both radiation and conduction due to the contact of the heating block over the glass disc. The required temperature should be approximately $40^{\circ} \mathrm{C}$ more than the melting temperature of the pump-out sealing material to seal the pump-out hole. In this modified design, the risk of dislocation of the heating block and the degradation of $\mathrm{O}$ rings due to continuous heating in the vacuum cup was reduced. Different types of materials such as silicone, Buna-N, Teflon or Viton are available, among which the Viton type is capable of sustaining temperatures up to $250^{\circ} \mathrm{C}$. The Viton $\mathrm{O}$ ring decomposes at temperature above $250^{\circ} \mathrm{C}$ causing ingress of gas molecules from the atmosphere, to reduce this the $\mathrm{O}$ ring was selected to be around $100 \mathrm{~mm}$ in diameter, placing the $\mathrm{O}$ ring sufficiently away from the heating element to avoid degradation. 


\section{Saim Memon}
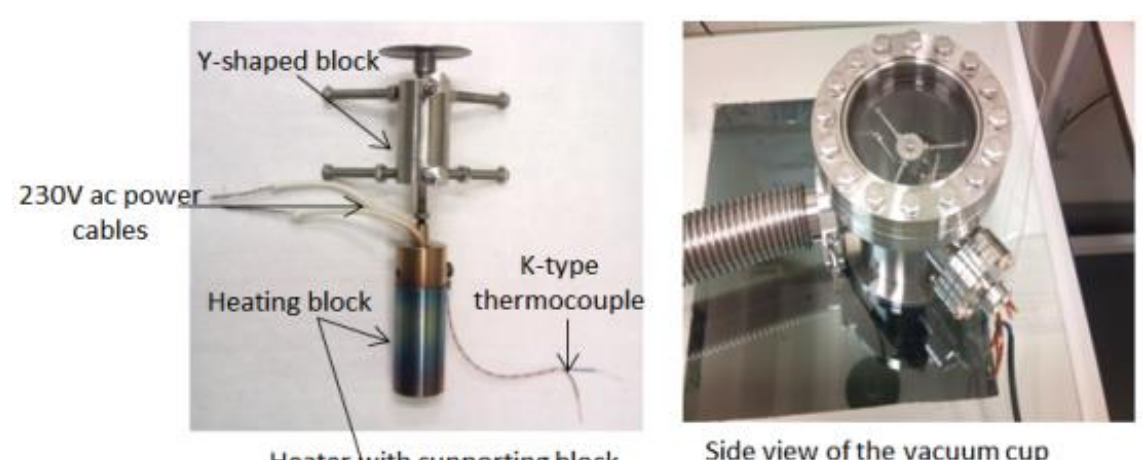

Side view of the vacuum cup

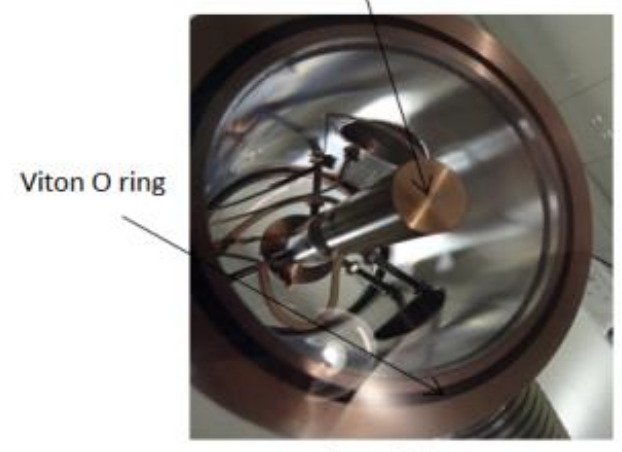

Bottom view of the vacuum cup

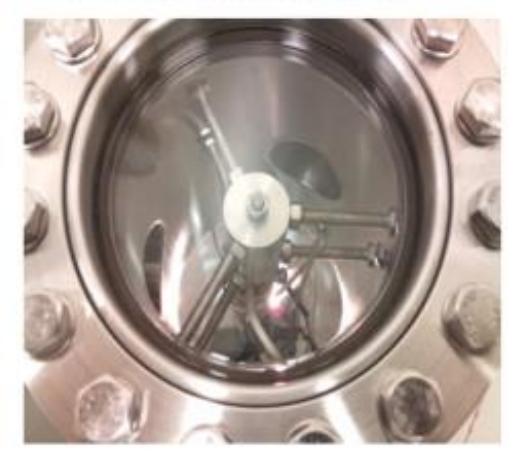

Top view of the vacuum cup

Fig. 3: Photographs of the vacuum cup system for the evacuation and sealing of the pump-out hole of a triple vacuum glazing.

\section{Fabrication Method}

A multiple stage fabrication method was developed, in which a number of samples were fabricated by using a newly developed dual-edge (low melt-temperature i.e. $186^{\circ} \mathrm{C}$ ) seal. It consists of $10 \mathrm{~mm}$ wide Cerasolzer CS186 as a main hermetic seal and a $4 \mathrm{~mm}$ wide J-B Weld epoxy steel resin as a support seal. This is because, under temperature gradients and high internal compressive and external tensile stresses, such support seal provides mechanical strength to the main seal. The fabrication method developed is as follows: (a) the glass sheets and glass-square cover slip for pump-out hole sealing were prepared by drilling a pump-out hole on the upper glass sheet, cleaning all three glass sheets with water, isopropanol and acetone and shaping the glass-square cover slip (Zhao et al, 2007); (b) the main seal around the periphery of bottom and middle glass sheet and on the glasssquare $(18 \mathrm{mmx} 18 \mathrm{~mm})$ was uniformly soldered; (c) the support pillars $(0.15 \mathrm{~mm}$ in height and $0.3 \mathrm{~mm}$ in diameter) in the square array spaced at $24 \mathrm{~mm}$ on the middle and lower glass sheets were placed (d) the three glass sheets were joined together by heating at $186^{\circ} \mathrm{C}$ for up to 2 hours in the oven (e) the assembly was allowed to cool down to ambient temperature of around $21^{\circ} \mathrm{C}$ followed by the use of epoxy J-B Weld to form the support seal (f) Two cavities between three hermetically sealed glass sheets were evacuated, using the high vacuum pump-out system, shown in Fig. 1; and (g) after the evacuation of $\sim 6$ hours at $50^{\circ} \mathrm{C}$ the pump-out hole was sealed by heating the glass square using the cartridge heater located inside the vacuum cup pump-out assembly. The hot plate was used to maintain the narrow temperature gradients on the glass surfaces to avoid glass facture. 


\section{Saim Memon}

\section{Experimental Results}

A fabricated sample of size $300 \mathrm{~mm}$ x $300 \mathrm{~mm}$, shown in Fig. 2a, is a result after four repeated trials and the sealing characteristics were found similar where the stress patterns, due to internal compressive and external tensile stresses, across the support pillars were observed indicated a vacuum-tight seal. The evacuated pressure achieved was $4.8 \times 10^{-2} \mathrm{~Pa}$ when subjected to the hot-plate temperatures set to $50^{\circ} \mathrm{C}$ as it improved the outgassing and avoided any damage to the glass sheets due to temperature gradients. However, temperature control has significance as when it increases above $50^{\circ} \mathrm{C}$ a high level of internal compressive stresses and external tensile stresses were observed that may cause a glass fracture. The evacuation pressure and hot plate temperature readings were recorded with respect to time at which the diaphragm and turbo-molecular pump achieves its ultimate pumping speed of up to 61 litres/sec as illustrated in Fig. 2 b.

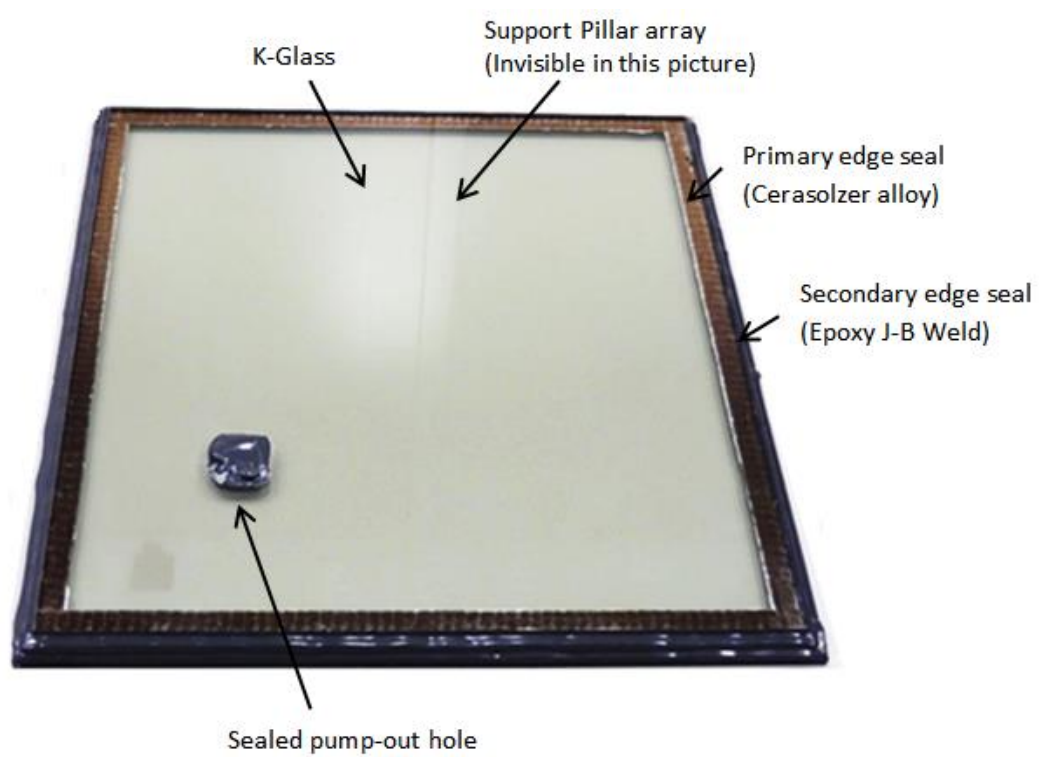

(a)

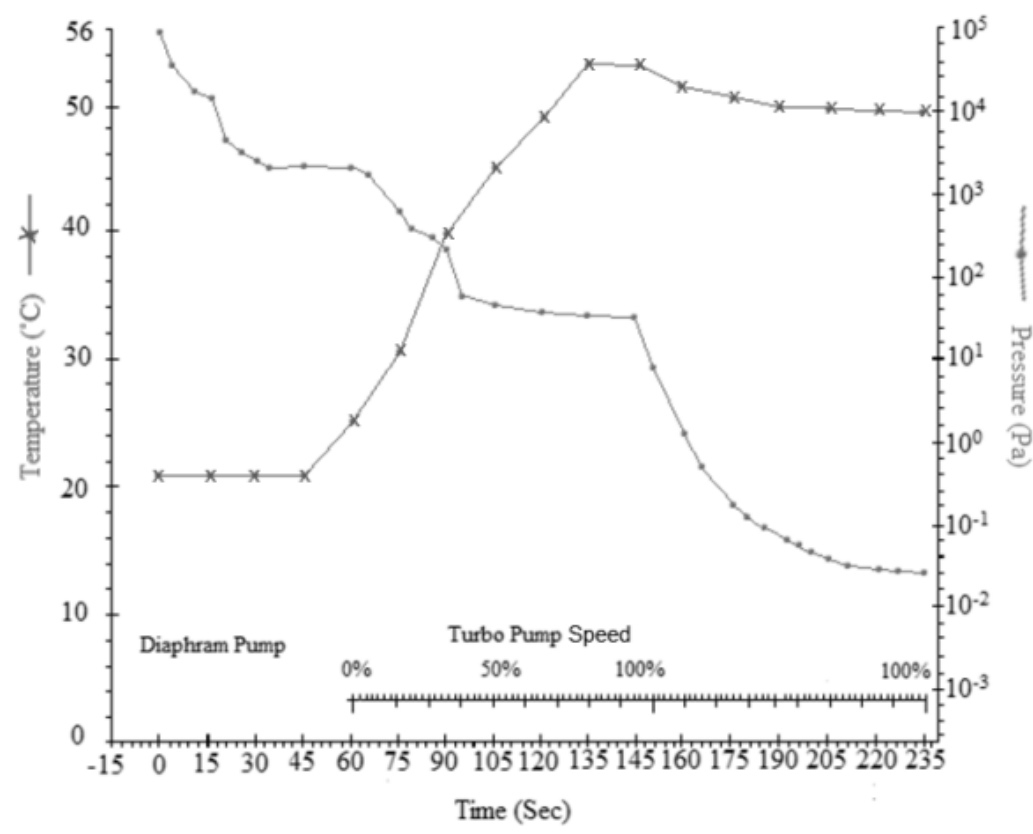

(b)

Fig. 2: (a) Fabricated dual-edge sealed triple vacuum glazing $(300 \mathrm{~mm} \times 300 \mathrm{~mm})$ and (b) the evacuation pressure and hot plate temperature readings with respect to the increment of pumping speed with diaphragm to the full-load pumping speed with turbomolecular pump. 


\section{Saim Memon}

\section{Thermal Performance Predictions}

A 3D finite-element model was developed, initially reported in Memon et al (2015), to predict the thermal performance based on the achievable vacuum pressure of $4.8 \times 10^{-2} \mathrm{~Pa}$ of the fabricated sample of size $300 \mathrm{~mm} \mathrm{x}$ $300 \mathrm{~mm}$. In order to reduce the computational time, only one quarter $(150 \mathrm{~mm} \times 150 \mathrm{~mm})$ of the triple vacuum glazing sample was modelled and simulated. The ASTM weather indoor and outdoor boundary conditions were employed in which the indoor and outdoor surface air temperatures were set to be at $21.1^{\circ} \mathrm{C}$ and $-17.8^{\circ} \mathrm{C}$ respectively in winter conditions. The internal and external surface heat transfer coefficients were set to 8.3 $\mathrm{Wm}^{-2} \mathrm{~K}^{-1}$ and $30 \mathrm{Wm}^{-2} \mathrm{~K}^{-1}$ respectively. The total $\mathrm{U}$ value and centre-of-pane $\mathrm{U}$ value equations employed are expressed in eq. 1 and eq. 2 .

$$
\begin{aligned}
& \mathrm{U}_{\text {centre }}=\frac{1}{\mathrm{Rsi}_{\text {centre }}+\frac{\mathrm{A}_{\text {centre }}\left(\mathrm{Ti}_{\text {centre }}+\mathrm{To}_{\text {centre }}\right)}{\mathrm{Q}_{\text {centre }}}+\mathrm{Rso}_{\text {centre }}} \\
& \mathrm{U}_{\text {total }}=\frac{1}{\mathrm{Rsi}_{\text {total }}+\frac{\mathrm{A}_{\text {total }}\left(\mathrm{Ti}_{\text {total }}+\mathrm{To}_{\text {total }}\right)}{\mathrm{Q}_{\text {total }}}+\mathrm{Rso}_{\text {total }}}
\end{aligned}
$$

Where, Rsi and Rso are the indoor and outdoor glazing surface thermal resistances, in $\mathrm{m}^{2} \mathrm{KW}^{-1} . \mathrm{A}_{\text {centre }}\left(\mathrm{m}^{2}\right)$ is the total glazing area minus the edge of glass areas (Fang et al, 2007). The thermal conductivity of Cerasolzer CS-186( Primary seal) and J-B Weld (secondary support seal) employed in the 3D finite element model are $46.49 \mathrm{Wm}^{-2} \mathrm{~K}^{-1}$ and $7.47 \mathrm{Wm}^{-2} \mathrm{~K}^{-1}$, respectively. The details of the experimental measurements of thermal conductivities of the edge sealing materials are reported elsewhere (Memon, 2017).

The centre-of-pane and overall $\mathrm{U}$-value of $0.33 \mathrm{Wm}^{-2} \mathrm{~K}^{-1}$ and $1.05 \mathrm{Wm}^{-2} \mathrm{~K}^{-1}$ for the fabricated triple vacuum glazing sample were predicted at the evacuated pressure of $4.8 \times 10^{-2} \mathrm{~Pa}$ having three $\mathrm{k}$ glass sheets (thermal conductivity of each $4 \mathrm{~mm}$ thick glass $1 \mathrm{Wm}^{-1} \mathrm{~K}^{-1}$ ) coated with $\mathrm{SnO}_{2}$ layer on the inner glass surfaces (emissivity of 0.15 ). The $\mathrm{G}$ value was predicted to be 0.71 . It was predicted in (Manz et al, 2006 and Fang et al, 2010) and demonstrated here that the glazing size, due to edge effects, influences the total U-value. A typical cold side isotherm of the model is shown in Fig $3 \mathrm{a}$ and the temperature distribution across support pillars is shown in Fig. $3 b$.

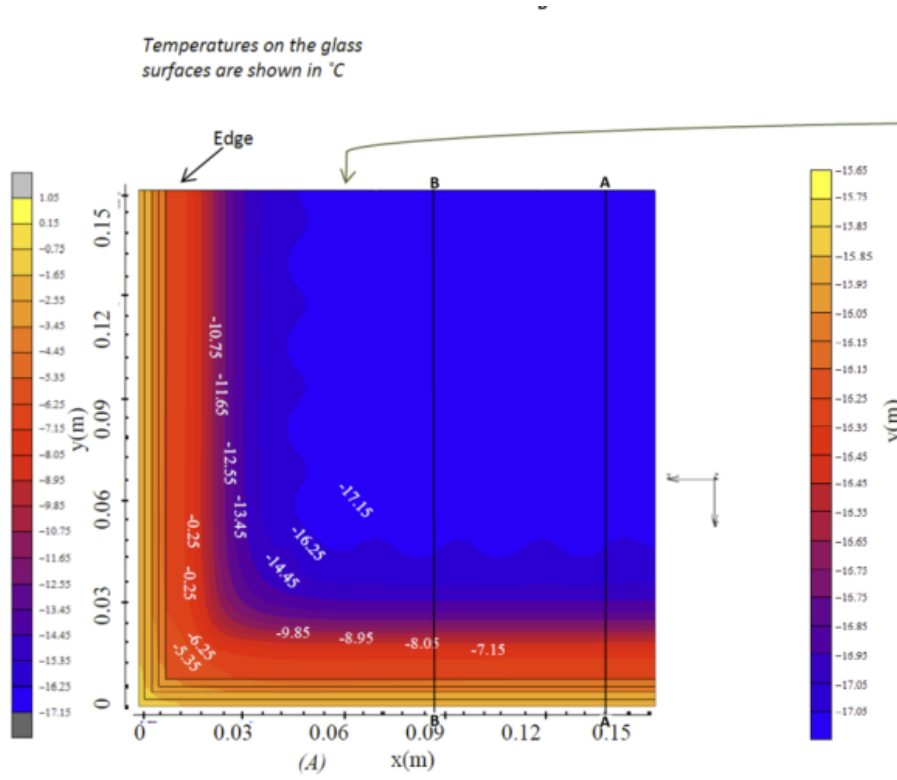

(a)

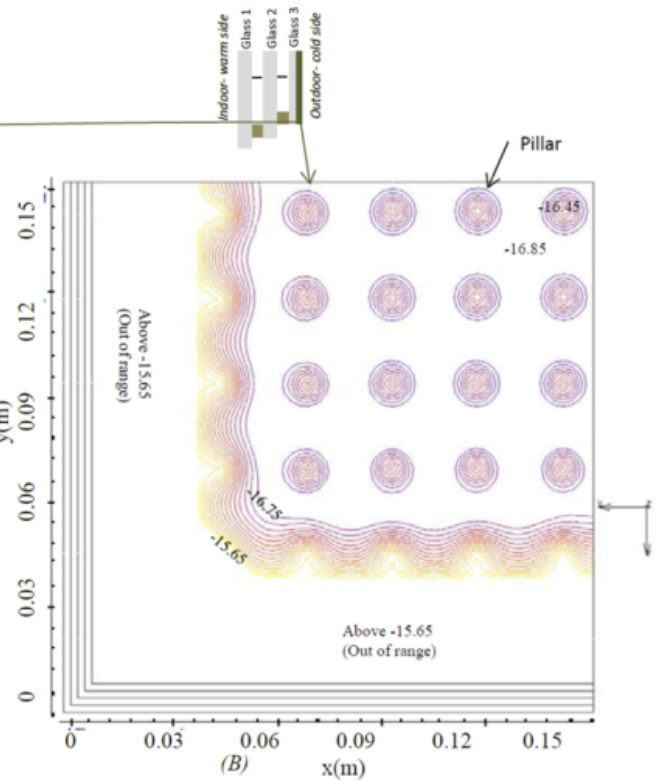

(b)

Fig. 3: The isotherms on the cold glass surface illustrates (a) the temperature changes from the edge sightline towards the centre of glass and (b) the temperature changes around support pillars on the centre of glass area of the triple vacuum glazing. 


\section{Saim Memon}

\section{Conclusions}

The experimental testing results have shown the achievable vacuum pressure in the vacuum system to be $4.35 \times 10^{-5} \mathrm{~Pa}$. This deviates by $7.7 \%$ with the ultimate vacuum pressure of the turbo molecular pump due to the molecular air flow conductances through the vacuum system. A vacuum cup designed to reduce the risk of dislocation of the heating block and the degradation of $\mathrm{O}$ rings due to continuous heating with the pump-out hole evacuation. The outcome of the design and development of high-vacuum system was the successful fabrication of ultra-low heat loss triple vacuum glazing with a pump-out hole sealing material using Cerasolzer CS-186. A new method of fabricating triple vacuum glazing based on a low melt temperature $\left(186^{\circ} \mathrm{C}\right)$ dual-edge seal was designed and experimentally validated, consisting of Cerasolzer CS186 alloy as a main seal and J-B Weld epoxy steel resin as a support seal. A vacuum pressure of $4.8 \times 10^{-2} \mathrm{~Pa}$ was achieved. A $3 \mathrm{D}$ FEM of the fabricated design of triple vacuum glazing was developed in which the centre-of-pane and overall U-values of a triple vacuum glazing $(300 \mathrm{~mm} \times 300 \mathrm{~mm})$ were predicted to be $0.33 \mathrm{Wm}^{-2} \mathrm{~K}^{-1}$ and $1.05 \mathrm{Wm}^{-2} \mathrm{~K}^{-1}$, respectively, based on three $\mathrm{SnO}_{2}$ coated K-glass sheets, these results are in agreement with the preceding reported results. Triple vacuum glazing has the potential in future, if manufactured at the mass production level, because of its slimness $(12.6 \mathrm{~mm})$ compared to the conventional glazings and due to its lowest achievable thermal transmittance value.

\section{References}

Allen, K., Connelly, K., Rutherford, P. and Wu, Y., 2017. Smart windows-Dynamic control of building energy performance. Energy and Buildings, 139, pp.535-546.

Andric, I., Pina, A., Ferrão, P., Fournier, J., Lacarrière, B. and Le Corre, O., 2017. The impact of climate change on building heat demand in different climate types. Energy and Buildings, 149, pp 225-234.

Baetens, R., Jelle, P. Gustavsen, A. 2011. Aerogel insulation for building applications: A state of the art review. Energy and Buildings, 43, pp 761-769.

Eames, P. C. 2008. Vacuum glazing: Current performance and future prospects. Vacuum, 82 pp 717-722.

Fang, Y., Hyde, T. J., Hewitt, N., 2010. Predicted thermal performance of triple vacuum glazing. Solar Energy, 84, pp 2132-2139.

Fang, F., Eames, P. C., Norton, B., Hyde, T. J., 2006. Experimental validation of a numerical model for heat transfer in vacuum glazing. Solar Energy, 80, pp 564-577.

Lee, J.R., Raymond, B., Bracegirdle, T.J., Chadès, I., Fuller, R.A., Shaw, J.D. and Terauds, A., 2017. Climate change drives expansion of Antarctic ice-free habitat. Nature, 547(7661), pp.49-54.

Memon S. 2014. Analysing the potential of retrofitting ultra-low heat loss triple vacuum glazed windows to an existing UK solid wall dwelling. Int. Journal of Renewable Energy Development, 3(3), pp 161-174. 


\section{Saim Memon}

Manz, H. 2008.On minimizing heat transport in architectural glazing. Journal of Renewable Energy, 33, pp 119128.

Memon, S., Farukh, F., Eames, P. C., Silberschmidt, V. V. 2015. A new low-temperature hermetic composite edge seal for the fabrication of triple vacuum glazing. Vacuum, 120, pp 73-82.

Memon, S. 2017. Experimental measurement of hermetic edge seal's thermal conductivity for the thermal transmittance prediction of triple vacuum glazing, Case Studies in Thermal Engineering, 10, pp 169-178.

Manz, H., Brunner, S., Wullschleger, L., 2006. Triple vacuum glazing: Heat transfer and basic mechanical design constraints, Solar Energy. 80, 1632-1642.

Memon, S and Eames, P.C. 2017. Solar Energy Gain and Space-Heating Energy Supply Analyses for SolidWall Dwelling Retrofitted with the Experimentally Achievable U-value of Novel Triple Vacuum Glazing. Journal of Daylighting, 4 (1), pp 15-25.

Piccolo, A. and Simone, F., 2015. Performance requirements for electrochromic smart window. Journal of Building Engineering, 3, pp.94-103.

Wu, L.Y., Zhao, Q., Huang, H. and Lim, R.J., 2017. Sol-gel based photochromic coating for solar responsive smart window. Surface and Coatings Technology, 320, pp.601-607.

Zhao, J. F., Eames, P. C., Hyde, T. J., Fang, Y., Wang, J. 2007. A modified pump-out technique used for fabrication of low temperature metal sealed vacuum glazing. Solar Energy 81, pp 1072-1077. 